\title{
Obituary for R. Bruce Thompson
}

\author{
Donald O. Thompson
}

Published online: 13 May 2011

(C) Springer Science+Business Media, LLC 2011

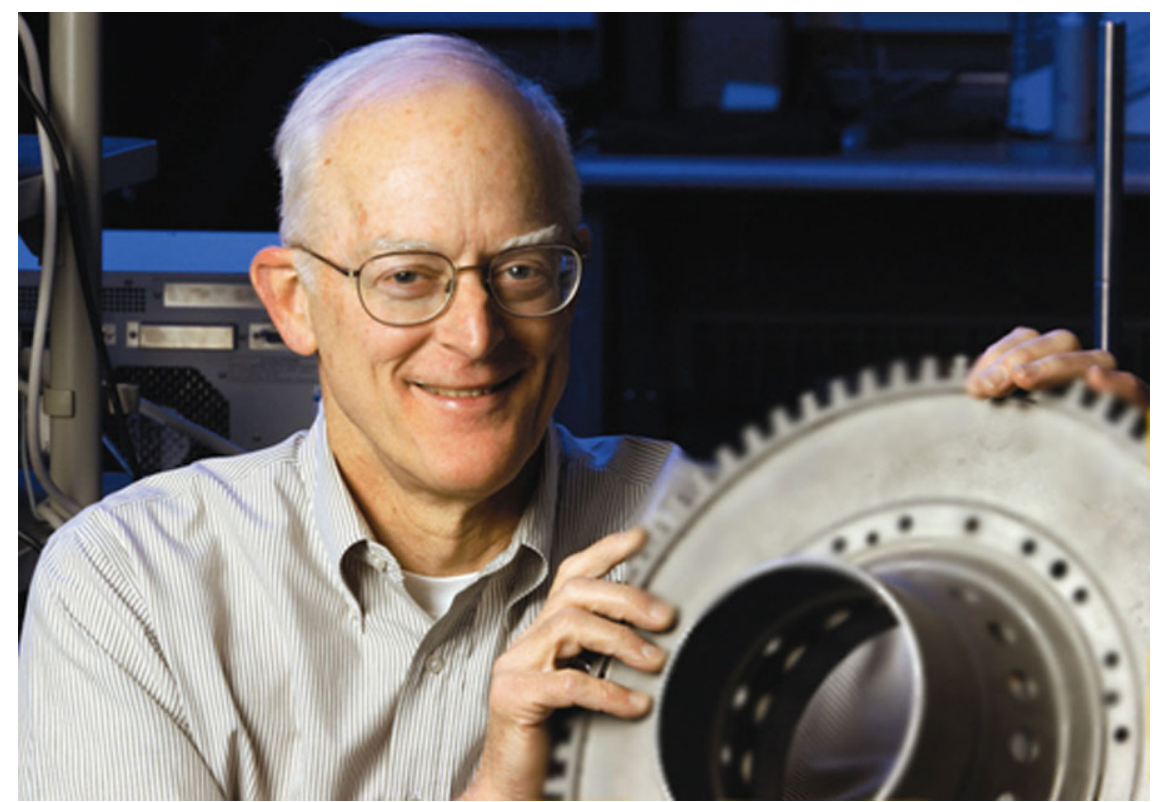

R. Bruce Thompson

Dr. R. Bruce Thompson, Director of the Center for Nondestructive Evaluation (CNDE) and Anson Marston Distinguished Professor of Materials Science and Engineering and Aerospace and Engineering Mechanics Engineering at Iowa State University in Ames, Iowa, and Editor of the Journal of Nondestructive Evaluation (JONE) died on March 7, 2011, due to the ravages of cancer. He was 69 years old leaving behind his wife Ann of Ames, Iowa; son Robert Kirk and wife

\section{D.O. Thompson $(\varangle)$}

Center for NDE, Iowa State University, Applied Sciences Complex II, 1915 Scholl Road, Ames, IA 50011, USA

e-mail: dothomp@iastate.edu
Leigh of Midland, Michigan; daughter Amy and husband Randy Standridge of San Antonio, Texas; five grandsons, Robert Kyle, Kolben Hatch, and Alexander Kerr Thompson, Erik Mathew and Andrew James Standridge. He is also survived by a sister, Nancy Bliss, and her husband John of Los Alamos, brother-in law Bill Dunkle and his wife Carol of Alamo, California, and several nieces and nephews. Additionally, Bruce leaves an extended global family of hundreds of friends, a rich legacy of high accomplishments, and a wealth of affection, admiration, and a heavy sense of loss amongst his many colleagues.

Bruce, as he was known to students, friends, and colleagues alike, was born to George and Marion Hatch on 
July 18, 1941, in College Station, Texas. His father was a well liked professor of Mechanical Engineering at Texas A\&M University and his mother a homemaker. He attended and graduated from A\&M Consolidated High School where he was both an excellent student and an active participant in the school's extracurricular programs. Basketball, tennis, and track were his specialties. After high school, Bruce attended Rice University in Houston, Texas, from which he graduated summa cum laude in Physics and ran the 880 meter track event. He then entered Stanford University where he earned a M.S. degree in Physics and a Ph.D. degree in Applied Physics. Bruce met and married Ann in 1967 while both were finishing their coursework there.

Bruce's professional research career began in 1970 when he accepted a position on the Technical Staff at the North American Rockwell Science Center (later the Rockwell International Science Center) in Thousand Oaks, California, after graduation from Stanford. He advanced rapidly to become Group Leader of Ultrasonic Applications and initiated new research in ultrasonics with emphasis upon the development of electromagnetic acoustic transducer (EMAT) technology, a subject in which he rapidly became a technical leader and in which he developed many patents. He was a strong supporter of NDE efforts throughout the Corporation and, particularly, its aerospace Divisions where the B-1 strategic bomber program required new NDE technology to meet and satisfy the very challenging damage tolerant design requirements for NDE that were derived from fracture mechanics principles. For the first time NDE capabilities to both "size" a flaw and to detect it with quantitatively known reliability were required. These newly placed demands upon NDE spurred theoretical and experimental efforts at the Science Center to understand and utilize elastic wave scattering from defects as a way to satisfy the new NDE requirements. Bruce played a key role in the development of this technology that came to be known as quantitative NDE. In 1980 Bruce joined the faculty at Iowa State University as part of a core group enlisted to advance the engineering science of NDE and to form the Center for NDE at that institution. During his years at Iowa State University Bruce became an internationally recognized leader in NDE with research specialties in theories of elastic wave scattering for sizing defects ("measurement models"), theories and practices for the NDE characterization of material properties including microstructural features using elastic waves, and the development of theories and practices for the determination of the Probability of Detection (POD) of "fatal" defects in structures by ultrasonic means. He served as graduate thesis advisor for 12 M.S. degree students, $22 \mathrm{Ph}$.D. degree students, and supervisor for 7 postdoctoral fellows. Bruce also played a key role in the development and teaching of undergraduate NDE courses and the first-of-its-kind NDE minor at Iowa State University. Bruce leaves a rich technical legacy of over 200 publications and critical reviews in refereed, edited journals, and book chapters as well as 24 patents.

Besides his research and teaching duties, Bruce was active in administering NDE activities at Iowa State University. From 1997 until his death on March 7, 2011, he served as Director of the Center for NDE and contributed significantly to the Center's growth and international prominence. $\mathrm{He}$ also served as co-organizer and host of the annual Review of Progress in Quantitative NDE and the meeting of the World Federation of NDE Centers. Additionally, Bruce served on many national boards in service both to the University and to federal agencies. Earlier, he served as Program Director of the Materials and Applied NDE Programs at Ames Laboratory (DOE) and as Associate Director of Science and Technology for Ames Laboratory. In 1988, he was appointed Editor of Springer's Journal of Nondestructive Evaluation and successfully managed it for 23 years. His many duties there included the hiring of editorial board members and their hosting at its annual meeting, reviewing papers, contributing papers, and delegating articles for review.

Bruce received many awards and honors from various organizations for his outstanding work. He was made a Fellow of the Institute of Electrical and Electronic Engineers (IEEE) in 1992. Iowa State University honored Bruce in 1997 by bestowing its highest faculty rank of Anson Marston Distinguished Professor of Engineering upon him and again in 2001 with its award of the D.R. Boylan Eminent Faculty Award for Research. In 2003 Bruce was elected to the National Academy of Engineering, the most prestigious award for engineers in the USA. The American Society for Nondestructive Testing (ASNT) honored him with the Lester Honor Lecture in 2004, the Tutorial Citation Award in 2006, and their Research Council Award for Sustained Excellence in 2007. The British Institute for Nondestructive Testing awarded him the President Honor Lecture and the Roy Sharpe Prize in 2006, and the Iowa Academy of Science presented him with the Distinguished Fellow Award in 2006. Iowa State University honored Bruce again in 2008 by naming him (and his wife Ann separately) as one of 150 Visionaries who have helped build Iowa State into today's University of Science and Technology. In 2009 Bruce earned the NDE Lifetime Achievement Award SPIE Structures/NDE for his many lifetime contributions to NDE.

Bruce was endowed with many gifts, all of which he honed and demonstrated to perfection. He led a life characterized by commitment and passion-his family, his work, outdoor activity and maps, and always new experiences. Intellectually, Bruce was a giant. He was equally at ease in initiating and discussing abstract physical theoretical concepts and in reciting Boston Red Sox statistics, his favorite sports team. Despite his intellectual prowess, Bruce was always humble, a genuine person with a heart of gold. His 
boundless wisdom was matched only by his warmth and willingness to share. As an active sports enthusiast, he specialized in running the $5 \mathrm{~K}$ at the annual QNDE conferences, skiing with his family near his second home in Colorado, and power-walking with his dog Neddie near the Center for NDE. Bruce was very capable of multitasking his many skills. The story goes that he was the only high school student in Texas to compete in the state slide rule competition and the state track meet on the same day-possibly simultaneously! Some of Bruce's greatest gifts were his interpersonal skills - his ability to communicate with clarity and his sense of fairness for all. Colleagues have said that he was unequaled in his ability to explain complicated and difficult to understand technical issues. Perhaps his greatest gift was his sense of fairness and its demand for justice for all. He always saw the best in any person's actions and always put the best construction on all that the person did. In doing so, he had a firm faith that "...things will work out."

Bruce leaves us with a rich legacy of family and friends, students and colleagues, technical work, and a philosophy for life built upon a wise use of bountiful gifts. He was very special—we will all miss his wisdom, sense of humor, and smile. 